\title{
Issues of Abbreviated Trial Application in Albania
}

\author{
Dr. Klodjan Skënderaj \\ University of Tirana \\ Dr. Sokol Mëngjesi
}

University of Tirana

\section{Doi:10.5901/ajis.2015.v4n1p189}

\begin{abstract}
Except the normal criminal procedure, the Albanian criminal procedure recognizes and provides the alternative trials rituals, or the alternative trial procedures, like the case of judging the case through an abbreviated trial. It must be underlined that "special trial" notion provided for an abbreviated trial is exactly referred to the cases of avoiding the rules of Criminal Procedure Code provided for an ordinary way of judgment. The procedure of abbreviated trial fundamentally consists in leaving the normal proceeding way of an ordinary trial, as this procedure of judicial examination is interrupted because of the request submitted by the defendant. In this paperwork some of issues encountered during the abbreviated trial will be treated theoretically and practically. A special importance will be given to specifying the subjects who can submit a request for abbreviated trial, the procedural moment of presenting this request. The way of presenting the request for an abbreviated trial and the considerations upon granting consent by the prosecutor will also be analyzed.
\end{abstract}

Keywords: abbreviated trial, defendant, condition of acts, reduce of $1 / 3$ of conviction, judicial examination

\section{The Legitimated Subjects Who Can Submit the Request for an Abbreviated Trial}

Article 403 of Criminal Procedure Code (Request for abbreviated trial) in its paragraf 1 cites that: "The defendant or his special attorney may require that the case terminates until the court examination starts".

In interpretation of this provision it is ascertained that the legitimated subjects to advance the request of proceeding with an abbreviated trial are the person taken as defendant himself, and his special lawyer as well.

In general in authoritarian doctrine (Islami, Hoxha, \& Panda, 2010)it is reasoned that in order to qualify the defendant's lawyer as legitimated to ask for an abbreviated trial, he must be supplied with a representation act, where it is expressively given the right to ask for abbreviated trial of criminal case. This conclusion of doctrine is based on interpretation made to article 50 paragraph 1 of Criminal Procedure Code, provision which provides that "The defense counsel enjoys the rights the law recognizes to the defendant, except those preserved to the latter in person."

Referring to this fact, it is reasoned that the defense can exercise all the law recognized powers of defendant, except those reserved to the latter personally, like may be the right to affirm the criminal act, the right not to be present in the hearing, the right to ask for an abbreviated trial, the right to make an appeal or not etj.

Following this reasoning regarding the presentation of the request for an abbreviated trial by the side of special lawyer, in another case (Ajazi, 2009) it is allowed the fact that when the defendant is judged in absentia, it is indispensable that the latter manifests his complete will (in his representation act) if he accepts for the process on his charge to be judged in abbreviated trial. This because by term special attorney, must be implied the defense authorized by the defendant himself and not a defense appointed by his family or familiars. In addition according to the same way of reasoning, in the representation act that means in the special power of attorney it must be clearly specified the delegation of the right to request among various proceeding ways, that of asking for having the case processed through abbreviated trial procedure.

However another part of doctrine (Haxhia, 2012), regarding proceeding with request for an abbreviated trial by the side of special attorney, argues that the request for an abbreviated trial in essential implies the expressed will to proceed with abbreviated trial which is also based on capability to search for the application of an alternative trial, influenced by "the situation in which the acts are found". According to this thinking line it is argued that, often during the judicial trials, in order to legitimize the attorneys in requesting an abbreviated trial, they ask to the latter a special power of attorney where it is specifically mentioned that the assigned attorney has the right to ask for this case to be eventually judged through 
procedure of abbreviated trial. Notwithstanding, according to this reasoning, this fact is not right, because considering even the meaning and effect of representation act, it brings as consequence the fact that the requirement made to defense lawyers by the judges if they have the right to ask for abbreviated trial or not as well, is not motivated by law. This, because when the defendant authorizes his lawyer through a representation act (power of attorney) is not necessary to be specified in this act even the right of asking for an abbreviated trial of the case on his charge. Once the lawyer is authorized to represent the defendant, he undertakes to practice all the rights and powers in possession of defendant starting from the phase of preliminary investigations and that of trial, implying this way even the right to ask for an abbreviated trial of eventual criminal case.

Although this recent viewpoint of doctrine must be taken with reserves, referring to the way of development of abbreviated trial, the consequences this kind of trial brings, but on the other side even the rights and procedural guarantees offered to the defendant.

Here we recall that the acceptance by the side of the court of the request to proceed with abbreviated trial brings like aforementioned, the benefit of reducing the conviction measure to one third, but on the other side it implies "giving up" from some of procedural guarantees for the defendant during the development of this kind of trial.

Considering that the trial held in abbreviated procedure (the consequences it brings because of giving the final sentence) affects directly to the rights of defendant, object of trial especially "the real and objective possibility" towards the sentence of conviction (without prejudice in any sporadic case giving the sentence of innocence), we think that the defendant conferring expressively the right to proceed with abbreviated trial to the defense appointed by him, can be a more correct choice in function of consequences that come for him from this alternative kind of trial.

We underline that here it is not prejudiced the possibility that the defendant who asks for an abbreviated trial, can even be declared not guilty in the final sentence, but virtually considering that this trial is held "with blocked evidences" and as a result there can't be any claims regarding the invalidity of evidences, the choice of sort of applied trial, must be an expression of authorized will by the side of the person, whose interests are directly affected.

\section{Way of Presenting the Request}

Paragraph 2 of article 403 of Criminal Procedure Code cites that: "The request is made in writing, whereas during the hearing orally. The written request is deposited in the secretary of the court at least three days before the date fixed for hearing".

Referring to above mentioned it is argued that this provision does not set limitations regarding the way of presenting the request for an abbreviated trial. Consequently, the defendant or his special attorney have the right to submit the request in written or verbally. If the request is required to be in written, the criminal procedural law conditions him with respecting a time term, within which the request must be deposited to the court secretariat, and actually at least three days before the day fixed for hearing.

From a doctrine's (Haxhia, Abbreviated trial and issues during its execution in practice, 2012) part it is argued that making the request in written is more advisable, as this way this is an indicator of evaluating seriousness regarding the criminal process. What's more, depositing the request in written, defining to the requiring subject even the term of its presentation, it implies the fact that the court must have the necessary time available to analyze the fact assessment, if the case can be solved "in the situation the acts are found". Although the law provides that the request for an abbreviated trial can be formulated even before the court verbally and in this case, the panel must guarantee that the will verbally expressed has to be transcribed in the verbal report of judicial hearing as well.

About the content of request, written or verbally made in judicial hearing, we recall that it must have some indispensable elements like the identity of defendant and of his attorney, the right legal reference of provisions of criminal procedure code about advancing the request for an abbreviated trial, the evidences on which basis the case is brought to be judged, the criminal file charged on defendant, and the right argument why the case can be resolved in the situation the facts are in the file of trial.

The criminal college of Supreme Court in its decision no. 671 date 15.11 .2006 reasoned that: "...regarding the rights of defendant in this sort of trial, except the presentation of conclusions with facts and legal arguments in final discussion (which as a rule, because of professionalism, he has, he is capable to present in higher level and clearer and more summarized than his client) being the attorney of defendant he can present a request for an abbreviated trial, whilst hearing, before judicial hearing starts, and when he is especially authorized in written (by a special power of attorney) to deposit it in written, to the secretariat of the court..." 


\section{Presentation of Request for an Abbreviated Trial}

The procedural moment of presenting the request for an abbreviated trial is of special importance because, not rarely in judicial processes the moment of presenting the request is confused because of various orientations regarding this condition. This fact has happened even from different interpretations of expression used in article 403 paragraph 1 of Criminal Procedure Code which underlines that "the defendant or his special attorney can ask for the case to be terminated until no judicial examination has started".

If we refer to the provisions of criminal procedure code it is concluded that the judicial examination, in the meaning of acts in judicial hearing, starts with "preliminary acts" provided in Section II, Chapter II (Judicial Examination), where the court after making the identification of the parties participating to the process, continues with hearing of preliminary requirements from prosecutor, the defendant or his attorney, and the private parties if there are any. At this moment the demands or claims of the parties are resolved concerning different procedural issues, which in no case have as object the resolution of claims on the merits of the case.

Onward the code continues with article 355 (Announcement of the opening of court examination) "After caring out the actions indicated in the article hereto, the chairman announces the judicial examination opened and explains the identity of the defendant and the accusation in his charge."

By the doctrine (Haxhia, Abbreviated Trial, 2010), it is argued that in many practical cases, it is wrong to include in this preliminary phase even the request for an abbreviated trial and as a result it is accepted that in case the defendant or his attorney, do not use the request for an abbreviated trial before the panel at this procedural moment of the trial, then they lose the right to ask for this later. This because considering the meaning and the goal of abbreviated trial, the request has sense when it is made at the moment when the prosecutor officially presents to the panel the request for judgment which is accompanied by the judging file, where are all the evidences gathered during the preliminary investigations.

In pursuance of above mentioned, considering the meaning and function of abbreviated trial procedure, it is argued that the request for this kind of trial has and takes sense when it is submitted at the moment when in court, the prosecutor propounds the request for the case judgment charged on defendant, listing together the evidences he wants to prove the charge with. So, only when the prosecutor submits the request for judgment of criminal case together with "catalog" of evidences in charge of defendant, we can say now we are "in a hearing of judicial examination"

In this meaning, in no case the term of "preliminary requirements" must be understood or included the request for an abbreviated trial. This because the request for an abbreviated trial, must be seen related to the start of judicial examination, or in other words related to analyzing one by one of all facts and evidences presented to the court.

It must be stressed out that this orientation is welcomed and in unison with logic interpretation of provisions of Criminal Procedure Code about abbreviated trial, because it sets as pre-condition the fact that only when this moment is exhausted, the prosecution continues with propounding the request for judgment, accompanied by the proofs through which the charge has to be proved before the court. Only at this moment it can be said that the phase of judicial examination has started.

In continue of opinion that the request for an abbreviated trial must be made when the prosecutor presents the request for judgment together with the accompanying evidences, it can be added that the prosecutor himself in his request for judgment can ask for the application of a mitigating or aggravating circumstance of criminal act, but hypothetically he can ask to add other evidences in their list as well or the contrary to reduce the evidences submitted before the court. In the end of this reasoning we think that the judicial examination starts exactly at the moment when the request for judgment is officially presented by prosecutor and when the court decides through an intermediate decision to accept the list of evidences presented by the side of prosecutor. In the same line of argument it is also valuable the ascertainment that once the request for abbreviated trial is accepted, the materials of investigating file are automatically transformed to a judicial file becoming so part of judging file. As a result the parties can base their claims on final conclusions, but at the same time it also serves to the court which can base its final decision on case judgment.

In addition the United Panels of Supreme Court in unifying decision no. 2 date 29.01 .2003 underline that "the judicial examination has not to do with the phase when the parties in process are appealed to submit their preliminary requests if they have any but it is related with the phase when the request for judgment together with evidences are submitted by the prosecutor before the court."

In conclusion we think that in interpretation of article 403 of the Criminal Procedural Code, the phase of judicial examination must not be considered related to the definitions of article 355 of Criminal Procedure Code, provision which is a constituent part of preliminary acts and which sanctions the opening of judicial examination, but this phase starts 
referring to article 359 of Criminal Procedure Code, where the court proceeds with taking the evidences presented by the representative of the charge.

We think that the frequent question if the judicial examination has started with an ordinary trial or it is or it is not possible to ask for change of judgment way by applying the abbreviated trial takes a negative answer. This happens because considering the judicial economy to be the real function which justifies the application of an abbreviated trial, if the case has proceeded with cross examination practicing the ordinary kind of trial then normally we can say that the court was invested to do the analysis of evidences of judging file. In this sense the evidences are analyzed through cross examination between the parties and as a consequence this fact is inconsistent with characteristics of abbreviated trial procedure.

The conclusion mentioned above is also based on opinion given by the United Colleges of Supreme Court where it is underlined that "....when the judicial examination has started with an ordinary trial, it cannot continue with an abbreviated one. This was a case with four defendants, where three of them have asked for abbreviated trial while the fourth has asked to continue with the ordinary one. At first the panel has judged correctly not accepting the request of an abbreviated trial, but afterwards has judged wrong when after completing the whole judicial investigation and the whole debate on administered evidences, the panel has accepted the request for abbreviated trial for three of defendants and has continued the ordinary trial for defendant S.O. In this case the panel has considered the notion of special trial wrong, because it has considered it only as a profit for defendant in reducing the measure of his conviction, unjustly admitting two kinds of trial in the same proceeding... The United Colleges of Supreme Court came to conclusion that in a judgment with some defendants, it cannot be proceeded with special trial for some and with ordinary one for the rest of them..."

In the long run, the doctrine seems to be unified regarding the determination of final moment of submitting the request for an abbreviated trial, concluding that this request must be submitted and admitted by the court even after the provisions of article 354 of Criminal Procedure Code are exhausted regarding the preliminary requests, or after the court has declared the judicial examination opened and where the parties have made their entry submissions together with the evidences to be administered in trial. At this point, the right of defendant to advance with the request for the kind of trial is expanded even after the court has the evidences available but on condition that it has not started to take and investigate the evidences provided by article 359 of Criminal Procedure Code yet.

There are opinions in our doctrine that the request for an abbreviated trial can be advanced even during the phase of preliminary investigations. This conclusion is based on fact that by term "in condition of acts" could be referred even during the phase of preliminary investigations, and as a result the defendant or his special attorney are legitimated to submit to the court the request on judging the case by proceeding with abbreviated (Avdulaj, 2004)trial since in investigating phase.

We think that this opinion must not be supported and as it is properly argued in another case, in the phase of preliminary investigations we cannot claim to submit a request for an abbreviated trial as in this phase the investigations acts are not completed all. This because we can be found in the conditions when the prosecutor has not managed to gather all the evidences and what's more the person who is being investigated may be unaware of the fact that preliminary investigations (Tartari, 2007) are being held about him. In the same parallel with this argument in another case (Ajazi, Procedural discussions that come out during the application of abbreviated trial, 2010) it is argued that the petition for an abbreviated trial cannot be submitted during the preliminary investigations because the abbreviated kind of trial can be chosen only after the investigation file becomes a judging file or differently saying this investigations file has gone to the court.

\section{The Opinion of Prosecutor Regarding the Request for an Abbreviated Trial}

In paragraph 6 of article 405 of Criminal Procedure Code it is stated that: "The prosecutor propounds the results of preliminary investigations synthetically and gives his opinion about the request of defendant".

Regarding the consent of prosecutor about the request of defendant on application of abbreviated trial, the doctrine argues that giving the consent by prosecutor is not an indispensable condition for the court to admit the application of this differentiate trial ritual.

This orientation is also embraced by another part of doctrine, which concludes that there are various viewpoints of charge representatives who give their consent and accept such request of defendant, or in other cases, state that they reject the beginning of abbreviated trial procedure.

The representatives of charge, when they are against the request of an abbreviated trial, seem not to be based on legal reasons when they refuse to accept the request for an abbreviated trial. This conclusion is reached because it is 
supposed that when the prosecutor presents his request for trial, together with the evidences on which it is based on, it is presumed by them that the evidences found in the judgment file are submitted completed and as a consequence they are considered to have been taken in conformity with all rules provided by the criminal procedure Code regarding gathering or fixation of them in the relevant verbal reports.

Our opinion is that in respect of request to proceed with an abbreviated trial, the prosecutor should have an "indifferent" attitude towards the acceptance or not of such request by the court, because the measure of conviction is not so important for him, but what counts is to declare the defendant guilty.

Moreover, regarding the consensus of prosecutor about acceptance by the court of the request for an abbreviated trial, the unifying practice of Supreme Court has stated that: "in interpretation of item 6 of article 405 of the Criminal Procedure Code, the consensus of prosecutor is not an indispensable condition for the court to accept the request of defendant to proceed with an abbreviated trial. This also justifies the right of prosecutor to make a complaint against the court decision for accepting the abbreviated trial, a complaint that may be submitted together with the complaint against the final decision".

Nevertheless, it must be underlined that in cases when the prosecutor declares to be against the acceptance of request for abbreviated trial, this must hold even the legal obligation to argue with reasons why the court must not approve such request. Only if this becomes a legal obligation for the prosecutor to argue the refusal of request by giving reasons, always if they really exist, it is possible to avoid in practice the abusive refusals regarding the request for an abbreviated trial.

\section{Conclusions}

In synthesis of this paperwork on abbreviated trial regarding the way of submitting the request for this kind of trial, we think that the formulation of request in written is more productive. This happens because it is an indicator or index of seriousness of defendant or of his defense.

Depositing the request in written setting to the petitioner even the term of its submission, allows to the court to have the necessary time available regarding the analyzing or assessment of evidences if the case can be resolved "in the situation in which the acts are actually found".

The defense assigned ex-officio is not legitimated to ask for an abbreviated trial, as he does not have the power to ask for this kind of special trial, considering this right to be closely linked to the expression of will of defendant. In this aspect the practice seems to reconfirm the rule on obligatory participation of defendant into the trial, reinforcing further the statement that only the defendant has the exclusive right to ask for this special trial.

In respect of the content of the request for an abbreviated trial, we recall that it must be argued and accompanied by the reasons why the case must be judged with the abbreviated trial procedure. So, the defendant and his defense have the obligation to accurately define the legal reference on which the request for an abbreviated trial is based on.

Regarding the determination of procedural moment when the judicial examination is considered started, considering it in function of advancing of the request for an abbreviated trial we think that in interpretation of article 403 of the Criminal Procedure Code, the phase of judicial examination must not be examined related to the provisions of article 355 of the Criminal Procedure Code, a provision which is a constituent part of preliminary acts and which sanctions the opening of judicial examination, but this phase (judicial trial) starts referring to article 359 of Criminal Procedure Code, where the court proceeds with taking evidences presented by the representative of charge. This conclusion is also based on doctrine arguments, which seems to be unified regarding the determination of final moment of submitting the request for an abbreviated trial, concluding that this request can be submitted and admitted by the court even when the provisions of article 354 of Criminal Procedure Code regarding the preliminary requirements are exhausted, or after the court has declared the judicial examination opened and where the parties have submitted their entry facts together with the evidences to be administered in this trial.

\section{References}

Ajazi, K. (2010). Procedural discussions that come out during the application of abbreviated trial. On some issues of criminal law and criminal procedural law , 146-147.

Ajazi, K. (2009). Special trials according to the code of criminal procedure. School of Magistrates , 53.

Avdulaj, D. (2004). Special Trials. Legal Tribune , 48.

Haxhia, M. (2010). Abbreviated Trial. Legal studies, 194.

Haxhia, M. (2012). Abbreviated trial and issues during its application into practice. Avokatia , 37-38. 
Haxhia, M. (2012). Abbreviated trial and issues during its execution in practice. Avokatia , 39.

Islami, H., Hoxha, A., \& Panda, I. (2010). Commentary of Criminal Procedure. Tirana: Morava.

Tartari, F. (2007). Abbreviated Trial, an alternative of judgment. Legal Studies, 77.

Unifying Decision of Supreme Court no. 2, date 29.01.2003

Decision of Criminal College of Supreme Court No. 671 date 15.11.2006 